\title{
Travel and Subjective Wellbeing: A Focus on Findings, Methods and Future Research Needs
}

\begin{abstract}
Subjectively experienced wellbeing has recently attracted increased attention in transport and mobility studies. However, these studies are still in their infancy and many of the multifarious links between travel behaviour and wellbeing are still under-examined; most studies only focus on one aspect of this link (i.e., travel satisfaction). In this paper we give an overview of studies concerning travel and wellbeing, focusing on results, methods and gaps in present research. We suggest that travel behaviour affects wellbeing through experiences during (destination-oriented) travel, activity participation enabled by travel, activities during (destination-oriented) travel, trips where travel is the activity, and through potential travel (or motility). The majority of empirical studies to date have been based on hedonic views of wellbeing, where pleasure and satisfaction are seen as the ultimate goal in life. They have paid little attention to eudaimonic views of wellbeing, which emphasise the realization of one's true potential, although this form of wellbeing can also be influenced by travel behaviour. We also argue that longer-term decisions, such as residential location choices, can affect wellbeing through travel. Travel options differ between different kinds of neighbourhoods, which can result in different levels of (feelings of) freedom and consequently different levels of subjective wellbeing. Since studies at present only show a subset of the travel behaviour-wellbeing interactions, we conclude the paper with an agenda for future research.
\end{abstract}

Keywords: Travel Behaviour, Wellbeing, Travel Satisfaction, Activities, Potential Travel, Residential Location Choice 


\section{Introduction}

Given that transport is the blood of society, it has long been accepted that (passenger) transport is intricately linked to the wellbeing of the economy, society and communities (Banister et al., 2011). Links between transport and accessibility on the one hand and wellbeing and quality of life at the level of individuals have also been recognised for several decades, and empirical studies focusing specifically on older people can be traced back to at least the early 1970s (Cutler, 1972; Carp, 1988). In recent years, however, research on how travel behaviour is associated with subjectively experienced wellbeing has gained new impetus. It is increasingly recognised that the former can affect the latter in at least five ways.

For one, individuals can experience positive or negative feelings when travelling to a destination (Abou-Zeid, 2009; Ettema et al., 2010): car drivers stuck in traffic can experience stress and impatience, whereas many will feel contentment and joy on trips in peaceful environments. But feelings experienced during travel are only the tip of the iceberg when it comes to the link between travel and wellbeing. Travel also increases wellbeing through the activity participation it enables, because persons' daily activities tend to be distributed across space, and given that needs are satisfied, social bonds strengthened and personal goals realised through activity participation (e.g., Archer et al., 2012; Ettema et al., 2010; Ravulaparthy et al., 2013). This second way in which travel behaviour shapes wellbeing implies that people who are unable to participate in activities (social exclusion) due to travel limitations may experience lower levels of wellbeing (Currie et al., 2010; Delbosc \& Currie, 2011) - a conclusion that can also be derived from Amartya Sen's capability approach (Sen, 1993; Nordbakke, 2013). Furthermore, there are experiential spill-over effects across travel and activity episodes (Bergstad et al., 2011; Ettema et al., 2010). A stressful or otherwise lowquality trip to an activity at a destination can adversely influence the execution of that activity and dampen the activity's wellbeing enhancing effect. Thirdly, destination-oriented travel can also be a context in which activities, mostly executed at stationary locations, can be performed working/studying or reading a book, for instance - which can affect the feelings experienced during travel and the evaluation of the trip (Ettema et al., 2012). Fourthly, additional complications arise when the sharp demarcation between travel and activity is challenged and travel is regarded as the activity as such, as is the case with recreational walking or cycling or with just driving around (Mokhtarian \& Salomon, 2001). This 'undirected travel' is usually non-mandatory and undertaken not so much to reach a destination as to increase satisfaction, joy or contentment through movement as such. Undirected travel can therefore contribute to wellbeing directly. 
Finally, over and beyond realised travel, people's motility - their capacity to become mobile (Kaufmann et al., 2004) - can affect their wellbeing (Nordbakke, 2013; Nordbakke \& Schwanen, 2013). For instance, having access to many transport resources (e.g., owning a car, living close to a public transit network) and having the knowledge and skill regarding their use can generate feelings of freedom, competence and belonging. Greater motility can also give people the idea and confidence that they are capable of realizing certain goals.

All five ways in which travel can affect wellbeing have been investigated in previous research, but not all to the same extent. Some studies have investigated the links between travel and wellbeing with statistical methods; others have employed qualitative data and interpretive methods. In this paper we provide an overview of studies concerning travel and wellbeing, focusing on substantive results and on the ways in which wellbeing has been understood and measured. The latter is quite important, given that there are many different ways in which wellbeing can be conceptualised. The paper's second objective is to provide an agenda for subsequent research into the links between travel behaviour and wellbeing. Here we will focus in particular on how travel choices are embedded in longer-term choices regarding the residential location.

The remainder of this paper is organized as follows. Section 2 explores the notion of wellbeing and discusses how this has been used and measured in the literature on travel and subjectively experienced wellbeing. Section 3 discusses substantive results regarding how travel affects subjective wellbeing, building on the five types of linkage discussed above and the two main approaches of wellbeing. The incorporation of longer-term decisions in studies of travel behaviour and wellbeing and the implications this may have for transport and land use policy are discussed in Section 4. The paper concludes with an agenda for research on travel behaviour and wellbeing.

\section{Wellbeing}

Wellbeing has a long history in (Western) philosophy, and ideas originally developed by thinkers like Epicurus, Aristotle and Bentham continue to inform contemporary thinking. Recently there has been a steady growth of interest in wellbeing in politics, policy-making, consumption and research, especially in advanced liberal democracies. Changes in wellbeing are increasingly seen as a more meaningful way of evaluating development, social progress and government policy than changes in economic output or GDP (Stiglitz et al., 2009; ONS, 2012), and a large industry of self-help books, courses and resorts that promise people greater wellbeing, wellness and happiness if they engage in certain sets of practices has come into existence (Binkley, 2011). Under the influence of the 'positive 
psychology' movement, wellbeing has become more and more seen as an individualised and subjectively experienced way of being, which is dependent on behaviours and objective circumstances (e.g. objective health, social and physical environment) and can be enhanced by changes in those behaviours and circumstances. Therefore, a subjective approach to wellbeing, using subjective indicators (e.g., satisfaction with income instead of income itself), is gaining increasing attention in wellbeing studies (e.g., Veenhoven, 2002). Whilst wellbeing has clear objective and collective dimensions (Atkinson et al., 2012; Nordbakke \& Schwanen, 2013), here we follow the increasingly mainstream view of wellbeing as an individual-subjective phenomenon.

\subsection{Hedonic and eudaimonic wellbeing}

With regard to subjectively experienced wellbeing, there exist two main intellectual traditions - the hedonic and eudaimonic approach. The hedonic view is based upon the idea that wellbeing consists of experiences of happiness or pleasure through the satisfaction of preferences and that people will try to maximize their wellbeing (Ryan \& Deci, 2001). The hedonic stance is clearly informed by the philosophical utilitarianism of Jeremy Bentham and classical philosophers like Aristippus of Cyrene and Epicurus. In contemporary research the Subjective Wellbeing (SWB) approach by Ed Diener and colleagues (Diener, 2009) and the work of Daniel Kahneman (Kahneman et al., 1999) are the most well-known representatives of the hedonic stance.

Wellbeing is more than preference satisfaction for eudaimonic thinkers, such as Aristotle. According to his Nichomachean ethics, wellbeing cannot be based on the extent of pleasure experienced but derives from the enactment of such qualities as excellence, virtue and self-realisation (Aristotle, 1980). Contemporary eudaimonic understandings of wellbeing build on Aristotle and emphasise purpose in and meaning of life, personal growth and 'flourishing' - the realisation of the best in oneself (Ryan \& Deci, 2001; Ryff \& Singer, 2008). On this view, wellbeing amounts to living in ways that reflect one's 'daimon' or true self, which becomes possible by "identifying one's potential strengths and limitations and choosing those goals that provide personal meaning and purpose in life" (Waterman et al., 2008: 42).

\subsubsection{Measuring hedonic wellbeing}

Academics commonly assume that hedonic wellbeing consists of three components (Diener, 2009): The presence of positive feelings, the absence of negative feelings and overall satisfaction with life. The first two components, often referred to as affective components, tend to pertain to shorter time 
frames; they detect self-reported feelings or emotions during an interval or activity episode. Satisfaction with life is a cognitive evaluation and pertains to the long term.

Two important scales for measuring shorter-term feelings are the Positive and Negative Affect Scale (PANAS) (Watson et al., 1988) and the Swedish Core Affect Scale (SCAS) (Västfjäll et al., 2002; Västfjäll \& Gärling, 2007). The PANAS asks respondents how they felt during the past few days or weeks, presenting them 10 descriptors for positive affects (e.g., proud) and 10 descriptors for negative affects (e.g., ashamed). The respondents are asked to rate (on a five-point scale) the extent to which they have experienced each mood state during a specified time frame, going from very slightly or not at all to very much (Watson et al., 1988). The SCAS measures core affects, which are argued to be instrumental for understanding emotions. Core affects vary along two orthogonal dimensions labelled valence (referring to pleasant vs. unpleasant affects) and activation (referring to affects varying from quietness to excitement). Respondents are asked to indicate how they felt at a particular moment and to rate this feeling on all the scales. The end-points of the valence scale were defined by three adjectives sad, depressed, displeased and glad, happy, pleased, respectively and the end-points of the activation scale dull, passive, sleepy and peppy, active, awake, respectively (Västfjäll et al., 2002; Västfjäll \& Gärling, 2007). However, both the PANAS and the SCAS can be criticised as the descriptors of the PANAS are only indirectly linked with positive or negative wellbeing. Additionally, not only do the end-points of the SCAS suffer from semantic imbalance; in a number of instances one of the end-points is widely taken to be desirable or good but the other not (as with, happy vs. depressed). ${ }^{1}$

A recent alternative to PANAS and SCAS is the Scale of Positive and Negative Experience (SPANE) (Diener et al., 2010). This scale asks respondents to which extent they experienced certain feelings e.g., positive, pleasant and negative - during a specific period. It is most comparable to PANAS but shorter (and therefore more user-friendly) and only uses words directly linked with positive or negative feelings. In the context of transport and time use research Ettema et al. $(2011,2012)$ and Olsson et al. (2013) have constructed a domain-specific scale for travel behaviour, the Satisfaction with Travel Scale (STS), which is based on the generic SCAS. The STS asks respondents how they felt during travel, using nine seven-point (Ettema et al., 2012; Olsson et al., 2013) or nine-point (Ettema et al., 2011) adjective scales, measuring positive activation versus negative deactivation, positive deactivation versus negative activation and an overall evaluation of travel.

\footnotetext{
${ }^{1}$ We thank one of the anonymous reviewers for raising these points.
} 
Overall satisfaction with life is mostly measured using the Satisfaction with Life Scale (SWLS) (Diener et al., 1985; Pavot \& Diener, 1993). This scale asks respondents to which extent they agree with five statements, including I am satisfied with my life. Responses are given on a seven-point scale, ranging from strongly disagree to strongly agree. In the transport context Bergstad et al. (2011) have constructed the Satisfaction with Daily Travel Scale (SDTS), which is based upon the SWLS. The statements of the SWLS were transformed into travel-related statements such as I am satisfied with my daily travel. An alternative for the SWLS is the Personal Wellbeing Index (PWI). This index contains eight items assessing one's level of satisfaction with seven theoretically derived quality-oflife domains: standard of living, health, achieving in life, relationships, safety, communityconnectedness and future security, as well as one global question asking: How satisfied are you with your life as a whole? Responses are made on a ten-point scale ranging from completely dissatisfied to completely satisfied (International Wellbeing Group, 2006; Stanley et al., 2011a).

\subsubsection{Measuring eudaimonic wellbeing}

The most well-known scale measuring eudaimonic wellbeing is the Personal Wellbeing (PWB) scale by Carol Ryff (1989), which assumes eudaimonic wellbeing to consist of six core dimensions: selfacceptance, positive relations with others, personal growth, purpose in life, environmental mastery and autonomy. These dimensions are measured using 32 items, including 'I possess a positive attitude to the self for self-acceptance. Respondents are asked to indicate to which extent they agree with the items, using a Likert-type scale ranging from strongly disagree to strongly agree (Ryff, 1989; Ryff \& Singer, 2008). However, not every study agrees on the six dimensions of eudaimonic wellbeing. In a study of Thai elders, Ingersoll-Dayton et al. (2004) established a different list of constituents of PWB: harmony, interdependence, respect, acceptance and enjoyment. Importantly, this lists combines interpersonal and intrapersonal components and is thus less individualistic than Ryff's original. This suggests that what constitutes wellbeing is time and place-specific and culturally inflected (see also Nordbakke \& Schwanen, 2013).

Further lists of constituents of eudaimonic wellbeing can be found in the literature. Waterman et al.'s (2008) Questionnaire for Eudaimonic Wellbeing (QEWB) identifies six constituents: self-discovery; perceived development of one's best potentials; a sense of purpose and meaning in life; investment of significant effort in pursuit of excellence; intense involvement in activities; and enjoyment of activities as personally expressive. The QEWB comprises 21 items to which respondents have to react by filling out five-point Likert-type scales. Diener et al. (2010) constructed a Flourishing Scale (FS) based upon five dimensions: social relationships; having a purposeful and meaningful life; self- 
respect and optimism; feelings of competence and engagement; and interest in daily activities. Respondents are asked to report to which extent they agree on eight statements on these five dimensions. The main advantage of this scale is that it is considerably shorter than the PWB scale. Ryan and Deci's (2000) self-determination theory (SDT), also embracing the concept of eudaimonia, posits three basic psychological needs - autonomy, competence, and relatedness - and theorises that fulfilment of these needs is essential for psychological growth, integrity and wellbeing, as well as the experiences of vitality and self-congruence.

\subsection{Methods of measurement}

Academic debates regarding subjectively experienced wellbeing are not limited to what is or should be measured; how wellbeing should be measured has also attracted considerable attention. An important distinction can be made between real-time measures and retrospective measures (AbouZeid, 2009). Real-time measures, such as the Experience Sampling Method (ESM) (Csikszentmihalyi \& Larsen, 1987; Scollon et al., 2003) and the Ecological Momentary Assessment (EMA) (Stone et al., 1999), ask for frequent and immediate reports of respondents in their normal surroundings. Retrospective measures, such as the Day Reconstruction Method (DRM) (Kahneman et al., 2004) and more traditional surveys, ask respondents to evaluate previous activities. The first methods have the advantage that they avoid distortions that affect the delayed recall and evaluation of experiences; the latter methods are cheaper to implement and reduce response burden (Kahneman et al., 2004).

\subsection{Travel behaviour studies}

For the purpose of this review we have traced published articles using Google Scholar (March/April 2012). The terms travel/mobility have been combined with wellbeing/quality of life/happiness/satisfaction (yielding eight unique combinations), which has led to the identification of 16 published articles. When revising the original submission we added three recent pieces on travel and wellbeing (Archer et al., 2012; Goulias et al., 2013; Ravulaparthy et al., 2013), resulting in a total of 19 articles. When these articles are evaluated, it becomes clear that past studies have almost exclusively relied on retrospective measurements and more specifically post-hoc surveys. To the best of our knowledge, there are as yet no published studies using ESM and EMA. In terms of what has been measured, it is equally evident that the literature is heavily biased towards hedonic understandings of wellbeing (Table 1). Only in the empirical work by Stanley and colleagues do we find attention for both hedonic and eudaimonic understandings of wellbeing. 
In light of travel behaviour research's strong roots in utility theory, this bias towards hedonic wellbeing is no surprise. But wellbeing is more than satisfaction and affect, and the activities that are enabled by travel and/or that people undertake during trips allow people to achieve purpose and meaning in life, to 'flourish' and to live in line with their 'daimon'. This is of course not to suggest that direct links between activity participation and hedonic wellbeing are absent. On the contrary, if people undertake interesting or rewarding activities, they are likely to feel more pleasant than unpleasant emotions, which can improve life satisfaction (Diener, 2000; Kahneman et al., 2004). Travel can affect both hedonic and eudaimonic aspects of wellbeing, and it is important to consider both types of wellbeing in future research. Recently, McMahan and Estes (2011) have combined hedonic aspects of wellbeing with eudaimonic aspects of wellbeing. They constructed the Beliefs about Wellbeing Scale (BWBS) to measure different aspects of wellbeing along four theoretically meaningful dimensions: the experience of pleasure; the avoidance of negative experience; selfdevelopment; and contribution to others. The use of such scales could give a deeper insight in the relationship between travel behaviour and wellbeing than scales that are only hedonic and eudaimonic in focus.

\section{Past empirical findings on travel and wellbeing}

As explained in the introduction, there are five ways in which travel behaviour can affect wellbeing. Here we will evaluate past findings regarding these ways and identify gaps insofar as these exist. To this end the section is divided into five sub-sections, focusing on: (1) Experiences during destinationoriented travel; (2) Activity participation enabled by travel; (3) Activities during destination-oriented travel; (4) Trips where travel is the activity; and (5) Potential travel (or motility).

\subsection{Experiences during destination-oriented travel}

The limited number of previous studies on travel and wellbeing mainly focus on travel satisfaction during commute trips. In contrast to SWB theory (Diener, 2009), the term satisfaction is sometimes used loosely by transport researchers to indicate both the cognitive and the affective evaluation of trips. ${ }^{2}$ Previous research shows that active travel seems to contribute to higher levels of travel

\footnotetext{
${ }^{2}$ In this paper we prefer to distinguish more strictly than in previous transport research between travel satisfaction as (primarily) a cognitive evaluation of people's trips and travel behavior and informed by reflective reasoning, and the positive/negative feelings associated with travel behavior as manifestations of what people experience with and through their corporeal body and as (primarily) non-reflective in nature. The primary reason for this is that this distinction is very common in the wider SWB research community. This is not to deny that questions about satisfaction may capture some degree of affective experience as the distinction between reflection and affectivity cannot be taken as absolute (McCormack \& Schwanen, 2012). It does, however, reflect our view that using the word 'satisfaction' in questions tends to prime survey participants to the
} 
satisfaction than motorized travel (Abou-Zeid, 2009; Duarte et al., 2010; Olsson et al., 2013). This might reflect that walking and cycling provide physical exercise, which diminish health risks and through hormonal stimulation, improves mood and reduces symptoms of depression and anxiety (Penedo \& Dahn, 2005).

There has also been considerable attention for possible differences in wellbeing between car and public transit use. Ettema et al. (2011) and Olsson et al. (2013), both using the Satisfaction with Travel Scale (STS), found higher degrees of travel satisfaction among car users than among public transit users. Using questionnaires collected in 2009 among 155 undergraduate students in Karlstad, Sweden, Ettema et al. (2011) compared commute travel satisfaction on hypothetical car trips with various kinds of hypothetical bus trips (differing in travel time and accessibility to bus stops). Travel satisfaction was higher among people who were assigned the car as travel mode for their hypothetical trips than those who were assigned the bus as hypothetical travel mode. However, satisfaction differs considerably and systematically across different types of hypothetical bus trips; shorter travel times and higher access to bus stops seems to increase travel satisfaction. Hypothetical car users also experience a more positive mood during the day and a higher level of satisfaction with life in general, although the mood during the day among hypothetical bus users with the most attractive trip conditions (e.g. short travel time) was almost as positive. These findings suggest a relationship between the experienced quality of travel and overall wellbeing (Ettema et al., 2011, 2012). In a study of 713 commuters in Stockholm, Göteborg and Malmö (Sweden), Olsson et al. (2013) confirm greater satisfaction with commuting by car than by public transit (type of public transit not specified).

Abou-Zeid (2009), using data from a web-based cross-sectional survey of 594 commuters (from different countries, especially the US), did not use the STS, but directly asked the respondents how satisfied they are with their commute (on a five-point Likert scale). Doing so, only the cognitive evaluation of commuters was measured. She states that individuals who commute by car are less satisfied than commuters who travel by public transportation (bus, metro or train). Car users experience less enjoyment and more stress, anxiety, impatience and anger while commuting. Besides, public transport - especially train - allows for engagement in activities (e.g., talking to others), resulting in positive feelings. ${ }^{3}$ This seems to suggest that the type of public transportation plays an important role. Duarte et al. (2010), presenting cartoons of diverse travel circumstances to

cognitive realm and that using such words as 'feeling' or 'happy' is likely to trigger more affective reactions from respondents.

${ }^{3}$ Activities during travel which are often associated with activities that people do at stationary locations will be discussed extensively in section 3.3. 
1084 respondents from various (especially European) countries, confirm this suggestion. They state that commute bus trips result in lower levels of satisfaction and commute trips with metro and train lead to higher levels of satisfaction compared with car trips.

Another set of findings pertains to travel time and satisfaction. Studies by Ettema et al. (2012) and Stutzer and Frey (2008) have found that trip duration tends to affect travel satisfaction negatively. With longer durations, travellers become less enthusiastic, less relaxed and they will evaluate the quality and efficiency of the trip lower (Ettema et al., 2012; Stutzer \& Frey, 2008). Furthermore, complicated trips (e.g., public transportation trips with transfers) can decrease the predictability and reliability of the trip and result in increased levels of stress, negatively affecting travel satisfaction (Wener et al., 2003).

In sum, from the limited literature that has been published to date it appears that travel satisfaction is likely to be shaped by and depend on: (i) travel mode choice (active travel contributing most to travel satisfaction, bus use contributing least); (ii) travel conditions (e.g., public transit services); and (iii) travel duration (longer durations resulting in lower travel satisfaction levels).

\subsection{Travel-facilitated activities}

Activity participation can increase both short-term affect and long term life satisfaction (Abou-Zeid \& Ben-Akiva, 2012; Diener, 2000; Lyubomirsky et al., 2005). Everyday activities help people to actualize their potentials and achieve personal growth and progress to their goals (Ettema et al., 2010). AbouZeid \& Ben-Akiva (2012) even claim that activities are planned and undertaken to satisfy needs so as to maintain or enhance well-being. Time use studies, using DRM, among 909 employed women (Kahneman et al., 2004) and 394 elderly couples (Goulias et al., 2013) indicate that leisure, social and relaxing activities are most enjoyable; paid work, household chores and other, more mandatory activities are less enjoyable. More recently White and Dolan (2009) have shown that pleasure levels of activities are not directly linked with reward levels; activities which are not pleasurable (e.g., working) can be very rewarding, and pleasurable activities (e.g., watching television) can be unrewarding. The studies by Kahneman et al. and White and Dolan also show that commuting is, compared with other daily activities, neither very pleasurable nor rewarding.

There is also direct evidence that out-of-home activity participation can enhance wellbeing. According to Archer et al. (2012), using a 2010 American time use survey, activities executed outside the home are associated with higher levels of happiness than activities inside the home. Spinney et 
al. (2009) and Ravulaparthy et al. (2013), for example, established statistically significant, positive correlations between the daily exposure to all kinds of out-of-home activities and wellbeing for, respectively, elderly non-working Canadians and senior American couples. In a time-geographical DRM study in Hong Kong Schwanen and Wang (2013) found that both the type of activity undertaken and the location - at home or outside the home and hence facilitated by travel - matters to subjectively experienced wellbeing; out-of-home activities and leisure/social activities result in higher levels of wellbeing than activities at home and more mandatory activities. According to Bergstad et al. (2011), using 1330 Swedish respondents, travel is related to wellbeing, but predominantly through activity participation. They found stronger correlations between satisfaction with out-of-home activities and subjective wellbeing than between travel satisfaction and subjective wellbeing. Not only the participation in activities, but also the way activities are executed affects wellbeing. Stress, time-pressure and hassles during trips to access out-of-home activities can increase negative feelings and can negatively affect the way in which the activity is carried out (Ettema et al., 2010). Bergstad et al. (2011) indicate that travel satisfaction is positively correlated with satisfaction with activities but also with weekly mood and subjective wellbeing. However, the relationship with weekly mood and subjective wellbeing is partly mediated by satisfaction with activities. This suggests that improvement in travel options, such as shorter travel and waiting times, may result in less time pressure, more efficient and less stressful performance of activities and ultimately greater well-being.

According to Abou-Zeid (2009), travel satisfaction can vary across different types of (leisure) activities. Travel satisfaction is highest for activities where individuals experience a high level of happiness when conducting that activity (e.g., eating out); however, this can be partly explained by the fact that respondents confound their liking for the activity with their liking of travel (Ory \& Mokhtarian, 2005). This suggests that travel satisfaction does not only affect satisfaction during activities; the anticipation of certain activities also influences travel satisfaction for trips to access those activities. In short, there are likely to exist significant spill-over effects across the activity and travel episodes that make up a daily activity-travel pattern. These effects can carry from the past into the present as a form of memory, or draw the (expected) future into the present through anticipation. These spill-over effects can also occur at multiple time-scales and need not be limited to the immediately preceding or subsequent activities and require more sustained attention in further research. 


\subsection{Activities during destination-oriented travel}

Not all activities are executed at the destination of a trip. Wellbeing enhancing activities can also be conducted while traveling to a destination, and there is growing empirical evidence that people use travel time to work, read, watch people, sleep and so forth (Lyons et al., 2007; Jain \& Lyons, 2008; Ohmori \& Harata, 2008). Activities during travel can also affect wellbeing. Ettema et al. (2012), using 996 questionnaires of inhabitants of Stockholm, Göteborg and Malmö (Sweden), analysed the influence of activities performed during travel on travel satisfaction among public transport users (train, bus, tram and metro). The respondents most frequently undertook relaxing and entertaining activities while travelling; working/studying, talking to others and using ICTs were performed less often. Talking to other passengers had the strongest positive effect on travel satisfaction as measured with the STS (see above), whereas commuters performing entertaining or relaxing activities experience low levels of travel satisfaction, possibly since engaging in these activities reflect unsuccessful attempts to abate boredom. However, the relationship between activities during (destination-oriented) travel and travel satisfaction was not straightforward; activities during travel may be undertaken not to make the trip more pleasant but to achieve satisfaction in other life domains at other times (Ettema et al., 2012). Therefore, it is not clear if activities during public transit trips can make public transit more attractive as an alternative for the private vehicle.

\subsection{Trips where travel is the activity}

Travel time is not always regarded as wasted time, but can be perceived and experienced positively (Archer et al., 2012; Jain \& Lyons, 2008; Ory \& Mokhtarian, 2005). This can result in trips where reaching the destination (to participate in certain out-of-home activities) is not the (main) goal of the trip; the demand for travel is not always as derived as commonly accepted. Travel is sometimes undirected and undertaken for its own sake because of its inherent value (Mokhtarian \& Salomon, 2001). Most of these trips are leisure activities (e.g., joyriding, recreational walking/jogging/cycling) but people can also take detours or avoid the quickest, most efficient route to enjoy scenic beauty or the environment, the sensation of movement or speed and/or the control and power that can be associated with movement. It is also possible that the demand for an activity may arise as a consequence of the desire to travel, meaning that the trip generated the activity (Ory \& Mokhtarian, 2005). For instance, people can decide to eat out instead of staying at home because they have a desire to get out and go somewhere.

Trips undertaken for the sake of travel can be expected to enhance wellbeing: they are likely to generate positive feelings in the short run and may also increase life satisfaction in the long run (e.g. 
through improvement of physical and mental fitness), perhaps more so than trips that are derived from the desire/need to undertake activities elsewhere in physical space. It is also conceivable that undirected trips contribute to eudaimonic wellbeing, as they may help provide meaning and purpose and assist in creating personal growth. However, as far as we are aware, there is no robust empirical evidence to substantiate these claims, and this is one avenue for further research.

\subsection{Potential travel}

Studies of the relationships between travel behaviour and wellbeing tend to focus on actually realised travel. However, examining the potential to move through space can also have implications for wellbeing, even if that potential is never actualised. This can be partly explained by the capabilities approach (Sen, 1993), according to which well-being can only be realized through freedom and the ability to conduct the activities and lead the life one values. As not being able to travel in the way one prefers (e.g., due to driving cessation) can imply that individuals cannot undertake activities they value, it can diminish well-being (see also Nordbakke, 2013). The potential to move can be referred to as motility, which comprises three elements (Kaufmann et al., 2004; Flamm \& Kaufmann, 2006): (i) access; (ii) competence; and (iii) appropriation. Access refers to the means of mobility that people have available and the ways in which their availability is constrained by place, time and other aspects of context. This dimension of motility has been shown to be related to both hedonic and eudaimonic wellbeing. On the basis of a study whereby 30 habitual car drivers in Switzerland were offered free public transport passes, Abou-Zeid et al. (2012) state that an increase in the possible ways of travelling can increase travel satisfaction. The relationship with eudaimonic wellbeing has been demonstrated in studies of the links between travel and social exclusion (Eisenberger et al., 2003; Lucas, 2012). Because of constrained travel options, vulnerable segments of the population - for instance, people on low incomes and elderly with limitations on physical or cognitive functioning- may not be able to participate in the (types of) activity they would like to undertake. This may not only lower satisfaction with travel, activities and life in general; it can also prevent them from flourishing by reducing access to key life-enhancing opportunities, such as employment, education, health and their supporting social networks. Transport disadvantages and not being able to be mobile have a negative indirect link with wellbeing, through social exclusion (Currie et al, 2010; Stanley et al., 2011a, 2011b).

The second and third element of motility - competence and appropriation - have been analysed less extensively in relation to wellbeing. Competence refers to the skills (know-how) and the cognitive knowledge necessary to travel, as well as the organisational capacity to plan activities and trips (e.g., 
being able to ride a bicycle, knowing where bus stops are). Appropriation refers to the way individuals interpret and act upon perceived or real access and skills; being able to travel in a desirable way will positively affect wellbeing. Appropriation also refers to attitudes; car lovers will probably generate higher levels of travel satisfaction (and resulting overall wellbeing) when travelling by car than people who prefer traveling by public transportation. Research with qualitative methods among older people nonetheless indicates that access, skills and appropriation are associated with wellbeing (Siren \& Hakamies-Blomqvist, 2009; Ziegler \& Schwanen, 2011; Schwanen et al., 2012). Being able to drive (a combination of access and competence) adds to wellbeing in later life, not simply because older people can get to places relatively easily but also because it allows them to be independent in the sense of not having to rely on others for getting around and strengthens decisional autonomy in that it becomes easier to make one's own decisions (appropriation). Competency and appropriation are, however, not necessarily associated positively with wellbeing. The study by Schwanen et al. (2012) among older people aged 70+ across the UK suggests that the appropriation of rides from other people can have counteracting impacts on wellbeing, with an ambiguous net effect. On the one hand this appropriation helps older people to access meaningful and satisfying activities elsewhere, but on the other hand often triggers guilt about imposing a burden on others, complicate power relations among individuals (by creating dependencies) and reduce self-esteem in older people. It would be useful to see the wellbeing impacts of access, competence and appropriation studied on a larger scale and for population segments other than older people and groups at risk of social exclusion.

\section{Incorporating longer-term processes in research on wellbeing and travel behaviour}

\subsection{The importance of the residential location}

It is important to consider the multiple time-scales implicated in the relationships between travel behaviour and wellbeing, if we are to better understand those associations. At least in the hedonic perspective, wellbeing itself is temporally complex and has short term (affect) and long term (life satisfaction) dimensions. This means that what is good or rewarding in the short run need not be satisfactory in the longer run. Consider, for instance, a person who drives to fast-food restaurants very often for the immediate pleasure eating hamburgers provides and who finds out in the longer term that his/her health is poor. Additionally, both life satisfaction and eudaimonic forms of wellbeing pertain to the long term, which means that non-repetitive short-term choices about activity and travel participation may often have limited impact on experienced wellbeing (which is likely to be shaped by many other processes as well). Only if such participation is very frequent and repetitive may there be a clear relation between travel behaviour and wellbeing. Moreover, it is well- 
known that travel choices are both constrained and enabled by longer-term choices regarding lifestyle, residential location, and so on (Salomon \& Ben-Akiva, 1983; Van Acker et al., 2010), and these are also related to, and sometimes revisited by people in light of, subjectively experienced wellbeing.

In this paper we concentrate specifically on residential location choices for two reasons. They set the parameters within which many travel choices - e.g., those regarding travel mode and destination choice - are made for both the individual and his/her household members, and they do so for considerable periods of time (given that many people do not move very frequently). In multipleworker households residential location often also impose restrictions on people's - especially women's - search space for employment and hence on the extent to which people can adjust their employment situation (e.g., Hanson and Pratt, 1995). Additionally, compared to longer-term choices pertaining to one's employment situation, car access or public transport car ownership, changes to where people live incur more costs for a larger number of individuals (Salomon and Mokhtarian, 1997): moving to another house involves greater monetary costs and non-monetary costs (i.e. disruption to everyday routines, neighbourhood-based social networks, sense of belonging and personal identity) to the whole household, and a greater share of these is borne by one's household members than with other long-term choices.

According to Ritsema van Eck et al. (2005), individuals living in high-density environments are better able to realise their daily activity programmes than those in low-density suburbs (for all modes of transport) due to shorter distances and greater accessibility. This might positively affect the wellbeing of individuals living in high-density setting compared to their counterparts in lower-density areas. Both the hedonic and the eudaimonic wellbeing of the former might be higher, given that individuals in higher-density settings can fulfil their daily obligations (e.g., chauffeuring children to and from school) with less effort and they can, within a given travel time budget, access a greater range of rewarding (leisure) activities enabling personal growth and flourishing, such as visiting a theatre, engaging in education/courses, and meeting friends and other social contacts. On the other hand, the benefits of greater access and shorter travel times can be offset by the experience of travelling in/through higher-density environments, as would be case when trips in such setting are much more stressful than in lower-density settings. This is why it is important to consider all five ways in which travel behaviour can affect wellbeing discussed above in studies of the linkages between wellbeing, travel and residential location choices. 
However, there also exists a direct relation between subjectively experienced wellbeing and residential location, which may offset many of the (travel-related) wellbeing benefits of high-density neighbourhoods. An increasing number of studies show that life satisfaction tends to be lower in larger cities characterised by greater density and diversity (Brereton et al., 2008; Dolan et al. 2008; Morrison, 2011). Various explanations have been offered for this relationship, including lower social capital, a great pace of everyday life and an overrepresentation of socioeconomic groups with lower levels of life satisfaction in large cities. Other studies have shown life satisfaction to be inversely related to density and accessibility to potential destinations from home, although effect sizes appear to be relatively small (Berry and Okulicz-Kozaryn, 2011; Schwanen and Wang, 2013). These studies suggest that it is important to avoid policies that seek to enhance wellbeing via travel behaviour in isolation. What is required is a set of integrative policies where the relation between transport and wellbeing is considered in conjunction with the associations of wellbeing with housing, employment, (fear of) crime, public service provision, and so on.

Residential location choice processes also mediate the links between travel and wellbeing through residential self-selection processes. Here the idea is that people select themselves into a certain neighbourhood which enables them to travel as much as possible with their preferred travel mode and thereby maximise their travel satisfaction. A person who prefers public transit, for instance, often has an affinity for urban residential neighbourhoods, as public transit is best organised in these urban areas (Handy et al., 2005; van Wee, 2009; De Vos et al., 2012). Self-selection might be prohibited due to income constraints, employment locations, local social networks that offer important help in reconciling work and home demands, and so forth; the result of this may be residential neighbourhood dissonance - a mismatch between the actual and preferred residential location (Schwanen \& Mokhtarian, 2004). It can be hypothesised that such mismatch may trigger negative feelings and reduce satisfaction with travel in the short run and, through the accumulation of negative momentary experiences, lower (hedonic) satisfaction with life wellbeing in the long run (e.g., Bergstad et al., 2011; Ettema et al., 2011; Olsson et al., 2013). Eudaimonic wellbeing can also be adversely affected. If mismatched residents feel hampered in their motility - i.e. if they feel their access is reduced and they disapprove of the transport modes whose use their actual location facilitates (appropriation) - they may participate less in the sort of activities that would be conducive to their flourishing. Consider someone living in an exurban location but with an 'urban heart' who would like to go to the art-house cinema every fortnight; his eudamonic wellbeing might be lower than it would have been, had he lived in or adjacent to a vibrant city centre offering a wide variety of leisure facilities. 
On the basis of the discussion so far we can develop a theoretical model of the links between travel and wellbeing (Fig. 1). In this model the longer-term decision-making processes of where to live affects persons' motility, which shapes their realised activity and travel patterns. People's general orientations towards transport, land use, the environment, family, labour and leisure affect both residential location decision-making and the appropriation dimension of individuals' motility (which refers to attitudes, values and beliefs regarding specific behaviours and acts). The model indicates that motility affects wellbeing both indirectly and directly. The indirect effect is through activity and travel patterns and the experience thereof; the direct effect reflects that the potential to travel in a particular way has value in and of itself. The latter can reflect option values (e.g., Laird et al., 2009) and the freedom, autonomy and independence that potential travel affords. The direct link from motility to activity and travel patterns of individuals reflects that greater (smaller) motility can facilitate (diminish) participation in certain activities and so enhance (reduce) both hedonic and eudaimonic wellbeing. Our model seeks to foreground that future travel behaviour research needs to consider both types of subjectively experienced wellbeing.

\section{<Figure 1 about here>}

Figure 1 also highlights that the links between travel-facilitated activities, activities undertaken during (destination-oriented) travel and trips where travel is the activity on the one hand and (positive/negative) feelings or experiences during (destination-oriented) travel (being part of hedonic wellbeing) on the other hand are two-directional. Those feelings are shaped by dimensions of activities and trips - the type of activity, the duration of activities, the persons with whom they are undertaken, the transport mode used, and so forth - as well as events that occur during activities and trips. But feelings also shape activity and travel patterns. For instance, such negative feelings as stress during travel can lead to immediate adjustments to people's activity and travel patterns (different route, cancelling a planned activity, etcetera) and can have a negative spill-over effect on the experience of subsequent activities and trips.

There are also feedback effects from wellbeing on residential location choice, general orientations, motility and activity patterns. These reverse effects indicate that people may decide to change their residential location, adjust their orientations and/or reconfigure their motility and activity patterns in order to increase their wellbeing. In one sense this idea resonates with the notion that people seek to maximise or optimise their utility, but in another there are critical differences: our understanding of wellbeing is not limited to satisfaction of needs or preferences and also incorporates eudaimonic aspects, and we consider the assumption that people in general deliberately maximize or optimize 
their wellbeing to be too strong. They may, as Abou-Zeid and Ben-Akiva (2012) claim, participate in certain activities in order to increase their wellbeing, but they will often do so in semi-conscious, instinctive ways and settle for acceptable rather than optimal outcomes. In our view, a more robust assumption is that they ensure that their wellbeing is not below some arbitrary, unobservable threshold, which will in most cases be socially constructed and relative to what others in one's lifeworld - friends, colleagues but also the images portrayed in the media, advertising, and so on experience or aspire (social comparison) (on the latter see Abou-Zeid \& Ben-Akiva, 2011; Ory et al., 2007).

\section{A research agenda}

Transport researchers have followed trends in other disciplines and started to pay increasing attention to subjectively experienced wellbeing and how this relates to travel behaviour. Important insights have been obtained but our literature review has also indicated that there are important omissions that have to be addressed. Further research can help to indicate how well-being data can be used in travel behavior models, and in transport project appraisal. In this concluding discussion we discuss six domains where we feel further research is needed.

The first of these pertains to the links between subjectively experienced wellbeing, travel behaviour and residential location choices; empirical research is needed to verify the mechanisms proposed in Figure 1. Particular attention should be paid to the ways in which residential self-selection and location dissonance mediate the relationships between wellbeing, travel behaviour and households' decision-making about where to live. Travel behaviour and the residential location (choice) are, however, only two of many possible contributions to one's wellbeing in addition to, for instance, health, social relations or type of employment. The effects of travel behaviour and residential location (choice) on wellbeing may thus be modest if not small. They are nonetheless important objects of research because travel behaviour and residential location choice can be influenced through interventions by policymakers, corporate actors and the third sector. Two further avenues for further research also follow from Figure 1. As stated repeatedly throughout this manuscript, it is important to consider both eudaimonic and hedonic wellbeing. We believe that scales including eudaimonic aspects of wellbeing, such as the Flourish Scale (Diener et al., 2010) and the Beliefs about Wellbeing Scale (McMahan \& Estes, 2011) can be combined fruitfully in future transport research with more familiar, hedonic scales (as discussed in section 2.1.1). Of the latter the use of recent scales such as SPANE (Diener et al., 2010) is to be preferred as these appear the most robust. Further experimentation with the extended versions of the Day Reconstruction Method that measure both 
hedonic and eudaimonic experiences (White \& Dolan, 2009; Schwanen \& Wang, 2013) at the level of individuals trips and activity episodes is also warranted in travel behaviour research. The other avenue following from Figure 1 is the need to construct quantitative measurements of motility and its constituents of access, competence and appropriation. These can then be incorporated in quantitative studies of the links between wellbeing and travel behaviour using advanced econometric methods, such as structural equation modelling (SEM).

A fourth domain of further research concerns the relationships between short-term feelings and longer-term wellbeing. We previously stated that spill-over effects may occur from the subjective experience of trips to the experience and performance of activities at the destination. It is, however, unclear how long these spill-over effects last: can a stressful travel to work negatively affect the work productivity during the rest of the day, or will only the first working hour be affected? Bergstad et al. (2011) even claim that weekly mood is affected by satisfaction with travel, and Schwanen and Wang (2013) find positive effects of the momentary experience of specific activity episodes on life satisfaction. The effects described in these two studies may not be direct; they may signify some form of accumulation of momentary experiences of repeatedly undertaken trips or activities. Reverse relationships are also possible: individuals with greater wellbeing are probably more satisfied with their travel and/or enjoy everyday activities to a greater extent. A bidirectional relationship seems to occur: a bottom-up causation, where particular variables (activities, social bonds) cause a certain level of wellbeing, and a top-down causation, where wellbeing produces a certain quality of outcomes (Diener, 1984; Feist et al., 1995; Headey et al., 1991). More research using panel rather than cross-sectional data and advanced econometric tools, such as Structural Equation Model (SEM), is needed to clarify these relations and the ways in which short and long-term aspects of subjectively experienced wellbeing are interrelated.

The fifth domain concerns the wellbeing implications of travel as a social activity. Little is known about how social contact with fellow travellers affects feelings during travel and longer-term hedonic and eudaimonic wellbeing. Ettema et al. (2012) state that talking to other passengers while using public transportation has a positive effect on travel satisfaction, while Goulias et al. (2013) find that travel as a passenger is consistently a pleasant activity while traveling alone is associated with both positive and negative feelings. However, further information is needed on how interaction between different categories of social tie (e.g., partner, friend, relative, colleague) during different types of travel (different travel modes and different types of destinations) can affect feelings and longer-term wellbeing. Carpooling with one's superior might be rather awkward and (much) more so than when travelling to a leisure activity with a friend. In some cases, people will carry out a certain activity at 
the destination of a trip together with their fellow traveller(s), increasing the link between travel (satisfaction) and activity (satisfaction). The implication of these speculations is that the growing number of studies on the links between social networks and travel behaviour (see Dugundji et al., 2008, 2011, 2012) should incorporate subjective wellbeing in their theoretical frameworks, data collection efforts and empirical analyses.

Finally, we believe that the wider (non-transport) literature on subjectively experienced wellbeing offers transport researchers to think in new, innovative ways about the evaluation of travel experiences. Based on empirical studies so far (Ettema et al., 2010; Stutzer \& Frey, 2008) it is tempting to conclude that reducing travel times will increase subjectively experienced wellbeing. The relationship between duration of a trip and wellbeing might be more complicated if Kahneman's peak-end rule (Fredrickson \& Kahneman, 1993; Kahneman et al., 1993) would be transferable to the transport domain. This rule states that the evaluation of a certain activity is not equal to the mean of all feelings experienced during that specific time frame; people especially tend to remember the extreme feelings during a certain activity. Additionally, unpleasant long experiences with a positive ending are evaluated less aversive than short unpleasant experiences (Kahneman et al., 1993). This could indicate that (i) minimizing travel time will not always result in higher travel satisfaction and might have potentially major implications for transport infrastructure appraisal (see also Banister, 2011), and (ii) slow, but satisfying travel modes (i.e., walking and bicycling) are being evaluated more positively than faster, less satisfying (motorized) travel modes. Further research could analyse if the most extreme and the final moments really determine the evaluation of different kinds of trips.

The peak-end rule can also explain why some individuals have a negative orientation towards public transport on the basis of a single experience (e.g., taking the wrong bus) when other trips with public transport were quite satisfying (Beirão \& Cabral, 2007; Hine \& Mitchell, 2001). By gaining more insight into the evaluation of different travel modes, these studies could help to improve the people's attitudes towards these modes. This could be achieved by incorporating subjectively experienced (hedonic) wellbeing and especially prior research on the peak-end rule into their theoretical frameworks.

\section{References}

Abou-Zeid, M. (2009). Measuring and Modeling Activities and Travel Well-being (doctoral dissertation). Massachusetts Institute of Technology, Cambridge, MA. 
Abou-Zeid, M., \& Ben-Akiva, M. (2011). The effect of social comparisons on commute well-being. Transportation Research Part A 45 (4), 345-361

Abou-Zeid, M. \& Ben-Akiva, M. (2012). Well-being and activity-based models. Transportation 39 (6), 1189-1207.

Abou-Zeid, M., Witter, R., Bierlaire, M., Kaufmann, V., \& Ben-Akiva, M. (2012). Happiness and travel mode switching: Findings from a Swiss public transportation experiment. Transport Policy 19 (1) 93104.

Archer, M., Paleti, R., Konduri, K. C., Pendyala, R. M., and Bhat, C. R. (2012). Modeling the connection between activity-travel patterns and subjective well-being. Working paper, University of Texas, Austin.

Aristotle (1980). The Nichomachean Ethics, translated by D. Ross (Oxford: Oxford University Press).

Atkinson, S., Fuller, S. \& Painter, J. (2012). Wellbeing and Place (Farnham: Ashgate).

Banister, D. (2011). The trilogy of distance, speed and time. Journal of Transport Geography 19 (4), 950-959.

Banister, D., Anderton, K., Bonilla, D., Givoni, M., \& Schwanen, T. (2011). Transportation and the environment. Annual Review of Environment and Resources 36, 247-270.

Beirão, G. \& Cabral, J. A. S. (2007). Understanding attitudes towards public transport and private car: a qualitative study, Transport Policy 14 (6), pp. 478-489.

Bergstad, C.J., Gamble, A., Gärling, T., Hagman, O., Polk, M., Ettema, D., Friman, M., \& Olsson, L.E. (2011). Subjective well-being related to satisfaction with daily travel. Transportation 38 (1), 1-15.

Berry, B.J.L., \& Okulicz-Kozaryn, A. (2011). An urban-rural happiness gradient. Urban Geography 32 (6), 871-883.

Binkley, S. (2011). Happiness, positive psychology and the program of neoliberal governmentality. Subjectivity 4 (3), 371-394.

Brereton, F., Clinch, P., \& Ferreira, S. (2008). Happiness, geography and the environment. Ecological Economics 65 (2), 386-396. 
Csikszentmihalyi, M., \& Larson, R. (1987). Validity and reliability of the experience sampling method. Journal of Nervous and Mental Disease 175 (9), 526-537.

Currie, G., Richardson, T., Smyth, P., Vella-Brodrick, D., Hine, J., Lucas, K., Stanley, J.R., Morris, J., Kinnear, R., \& Stanley, J.K. (2009). Investigating links between transport disadvantage, social exclusion and well-being in Melbourne - Preliminary results. Transport Policy 16 (3), 97-105.

Currie, G., Richardson, T., Smyth, P., Vella-Brodrick, D., Hine, J., Lucas, K., Stanley, J.R., Morris, J., Kinnear, R., \& Stanley, J.K. (2010). Investigating links between transport disadvantage, social exclusion and well-being in Melbourne - Updated results. Research in Transportation Economics 29 (1), 287-295.

Cutler, S.J. (1972). The availability of personal transportation, residential location, and life Satisfaction. Journal of Gerontology 27 (3), 383-389.

Delbosc, A., \& Currie G. (2011). Transport problems that matter - social and psychological links to transport disadvantage. Journal of Transport Geography 19 (1), 170-178.

De Vos, J., Derudder, B., Van Acker, V., \& Witlox, F. (2012). Reducing car use: changing attitudes or relocating? The influence of residential dissonance on travel behavior. Journal of Transport Geography 22, 1-9.

Diener, E. (1984). Subjective well-being. Psychological Bulletin 95 (3), 542-575.

Diener, E. (2000). Subjective well-being: the science of happiness and a proposal for a national index. American Psychologist 55 (1), 34-43.

Diener, E. (2009) The Science of Well-Being: The Collected Works of Ed Diener, Volume 1. Dordrecht: Springer.

Diener, E., Emmons, R.A., Larsen, R.J., \& Griffen, S. (1985). The satisfaction with life scale. Journal of Personality Assessment 49 (1), 71-75.

Diener, E., Wirtz, D., Tov, W., Kim-Prieto, C., Choi, D.-W., Oishi, S., \& Diener-Biswar, R. (2010). New well-being measures: short scales to assess flourishing and positive and negative feelings. Social Indicators Research 97 (2), 143-156. 
Dolan, P., Peasgood, T., \& White, D. (2008). Do we really know what makes us happy a review of the literature on the factors associated with subjective well-being. Journal of Economic Psychology 29 (1), 94-122.

Duarte, A., Garcia, C., Giannarakis, G., Limão, S., Polydoropoulou, A., \& Litinas, N. (2010). New approaches in transportation planning: happiness and transport economics. Netnomics 11 (1), 5-32.

Dugundji, E., Páez, A., \& Arentze, T. (2008). Social networks, choices, mobility, and travel. Environment and Planning B 35 (6), 956-960.

Dugundji, E., Páez, A., Arentze, T., Walker, J.L., Carrasco, J.A., Marchal, F., \& Nakanishi, H. (2011). Transportation and social interaction. Transportation Research Part A 45 (4), 239-247.

Dugundji, E., Scott, D.M., Carrasco, J.A., \& Páez, A. (2012). Urban mobility and social-spatial contactintroduction. Environment and Planning A 44 (5), 1011-1015.

Eisenberger, N.I., Lieberman, M.D., \& Williams, K.D. (2003). Does rejection hurt? An fMRI study of social exclusion. Science 302 (5643), 290-292.

Ettema, D., Friman, M., Gärling, T., Olsson, L.E., \& Fujii, S. (2012). How in-vehicle activities affect work commuters' satisfaction with public transport. Journal of Transport Geography 24, 215-222.

Ettema, D., Gärling, T., Eriksson, L., Friman, M., Olsson, L.E., \& Fujii, S. (2011). Satisfaction with travel and subjective well-being: development and test of a measurement tool. Transportation Research Part F 14 (3), 167-175.

Ettema, D., Gärling, T., Olsson, L.E., \& Friman, M. (2010). Out-of-home activities, daily travel, and subjective well-being. Transportation Research Part A 44 (9), 723-732.

Feist, G.J., Bodner, T.E., Jacobs, J.F., Miles, M., \& Tan, V. (1995). Integrating top-down and bottom-up structural models of subjective well-being: a longitudinal investigation. Journal of Personality and Social Psychology 68 (1), 138-150.

Flamm, M., \& Kaufmann, V. (2006). Operationalizing the concept of motility: a qualitative study. Mobilities 1 (2), 167-189.

Fredrickson, B.L., \& Kahneman, D. (1993). Duration neglect in retrospective evaluations of affective episodes. Journal of Personality and Social Psychology 65 (1), 45-55. 
Goulias, K.G., Ravulaparthy, S., Polydoropoulou, A. \& Yoon, S.Y. (2013). An exploratory analysis of on the time-of-day dynamics of episodic hedonic value of activities and travel. Paper presented at 92nd Annual Meeting of Transportation Research Board, Washington D.C.

Handy, S.L., Cao, X., \& Mokhtarian, P.L. (2005). Correlation or causality between the built environment and travel behavior? Evidence from Northern California. Transportation Research Part $D$ $10(6), 427-444$.

Hanson, S., Pratt, G.J. (1995). Gender, Work and Space. New York: Routledge.

Headey, B., Veenhoven, R., \& Wearing, A. (1991). Top-down versus bottom-up theories of subjective well-being. Social Indicators Research 24 (1),81-100.

Hine, J., \& Mitchell, F. (2001). Better for everyone? Travel experiences and transport exclusion. Urban Studies 38 (2), 319-332.

Ingersoll-Dayton, B., Saengtienchai, C., Kespichayawattana, J., \& Aungsuroch, Y. (2004). Measuring psychological well-being: insights from Thai elders. The Gerontologist 44 (5), 596-604.

International Well-being Group (2006). Personal well-being index. Australian Centre on Quality of Life. Melbourne: Daekin University.

Jain, J., \& Lyons, G. (2008). The gift of travel Time. Journal of Transport Geography 16, 81-89.

Kahneman, D., Diener, E., \& Schwartz, N. (1999). Well-Being: The Foundations of Hedonic Psychology. New York: Russell Sage Foundation.

Kahneman, D. Fredrickson, B.L., Schreiber, C.A., \& Redelmeier, D.A. (1993). When more pain is preferred to less: adding a better end. Psychological Science 4 (6), 401-405.

Kahneman, D., Krueger, A.B., Schkade, D.A., Schwarz, N., \& Stone, A.A. (2004). A survey for characterizing daily life experience: the day reconstruction method. Science 306 (5702), 1776-1780.

Kaufmann, V., Bergman, M.M., \& Joye, D. (2004). Motility: mobility as capital. International Journal of Urban and Regional Research 28 (4), 745-756.

Laird, J., Geurs, K., \& Nash, C. (2009). Option and non-use values and rail project appraisal. Transport Policy 16 (4), 173-182.

Lucas, K. (2012). Transport and social exclusion: where are we now? Transport Policy 20, 105-113. 
Lyons, G., Jain, J., \& Holley, D. (2007). The use of travel time by rail passengers in Great Britain. Transportation Research Part A 41 (1), 107-120.

Lyubomirsky, S., Sheldon, K.M., \& Schkade, D. (2005). Pursuing happiness: the architecture of sustainable change. Review of General Psychology 9 (2), 111-131.

McCormack, D.P., \& Schwanen, T. (2011). The space-times of decision making. Environment and Planning A 43 (12), 2801-2818.

McMahan, E.A., \& Estes, D. (2011). Measuring lay conceptions of well-being: the beliefs about wellbeing scale. Journal of Happiness Studies 12 (2), 267-287.

Mokhtarian, P.L., \& Salomon, I. (2001). How derived is the demand for travel? Some conceptual and measurement considerations. Transportation Research Part A 35 (8), 695-719.

Morrison, P.S. (2011). Local expressions of subjective well-being: the New Zealand experience. Regional Studies 45 (8), 1039-1058.

Nordbakke, S. (2013). Capabilities for mobility among urban older women: barriers, strategies and options. Journal of Transport Geography 26, 166-174.

Nordbakke, S., \& Schwanen, T. (2013). Wellbeing and mobility: a theoretical framework and literature review focusing on older people. Mobilities, in press.

Ohmori, N., \& Harata, N. (2008). How different are activities while commuting by train? A case in Tokyo. Tijdschrift voor Economische en Sociale Geografie 99 (5), 547-561.

Olsson, L.E., Gärling, T., Ettema, D., Friman, M., \& Fujii, S. (2013). Happiness and satisfaction with work commute. Social Indicators Research 111 (1), 255-263.

ONS (2012). First ONS Annual Experimental Subjective Well-being Results, Available at: http://www.ons.gov.uk/ons/dcp171766 272294.pdf.

Ory, D.T., \& Mokhtarian, P.L. (2005). When is getting there half the fun? Modeling the liking for travel. Transportation Research Part A 39 (2-3), 97-123.

Ory, D.T., Mokhtarian, P.L., \& Collantes, G.O. (2007). Exploring the cognitive and affective mechanisms behind subjective assessments of travel amounts. Environment and Behavior 39 (4), 494-528. 
Pavot, W., \& Diener, E. (1993). Review of the satisfaction with life scale. Psychological Assessment 5 (2), 164-172.

Penedo, F.J., \& Dahn, J.R. (2005). Exercise and well-being: a review of mental and physical health benefits associated with physical activity. Current Opinion in Psychiatry 18 (2), 189-193.

Ravulaparthy, S., Yoon, S.Y. \& Goulias, K.G. (2012). Linking elderly transport mobility and subjective well-Being: A multivariate latent modeling approach. Paper presented at 92nd Annual Meeting of Transportation Research Board, Washington D.C.

Ritsema van Eck, J., Burghouwt, G., Dijst, M. (2005). Lifestyles, spatial configurations and quality of life in daily travel: an explorative simulation study. Journal of Transport Geography 13 (2), 123-134.

Ryan, R.M., \& Deci, E.L. (2000). Self-determination theory and the facilitation of intrinsic motivation, social development, and well-being. American Psychologist 55 (1), 68-78.

Ryan, R.M., \& Deci, E.L. (2001). On happiness and human potentials: a review of research on hedonic and eudaimonic well-being. Annual Review of Psycology 52, 141-166.

Ryff, C.D. (1989). Happiness is everything, or is it? Explorations on the meaning of psychological wellbeing. Journal of Personality and Social Psychology 57 (6), 1069-1081.

Ryff, C.D., \& Singer, B.H. (2008). Know thyself and become what you are: a eudaimonic approach to psychological well-being. Journal of Happiness Studies 9 (1), 13-39.

Salomon, I., \& Ben-Akiva, M. (1983). The use of the life-style concept in travel demand models. Environment and Planning A 15 (5), 623-638.

Salomon, I., Mokhtarian, P.L. (1997). Coping with congestion: understanding the gap between policy assumptions and behaviour. Transportation Research Part D 2 (2), 107-123.

Schwanen, T., Banister, D., \& Bowling, A. (2012). Independence and mobility in later life. Geoforum $43(6), 1313-1322$.

Schwanen, T., \& Mokhtarian, P.L. (2004). The extent and determinants of dissonance between actual and preferred residential neighborhood type. Environment and Planning B 31 (5), 759-784.

Schwanen, T., \& Wang, D. (2013). Well-being, social contacts and everyday activities in space and time. Manuscript submitted for publication, copy available form tim.schwanen@ouce.ox.ac.uk. 
Scollon, C.N., Kim-Prieto, C., \& Diener, E. (2003). Experience sampling: promises and pitfalls, strengths and weaknesses. Journal of Happiness Studies 4 (1), 5-34.

Sen, A. (1993). Capability and well-Being. In M. Nussbaum, A. Sen (Eds), The Quality of Life (pp. 3053). Oxford: Clarendon Press.

Siren, A., \& Hakamies-Blomqvist, L. (2009). Mobility and well-being in old age. Topics in Geriatric Rehabilitation 25 (1), 3-11.

Spinney, J.E.L., Scott, D.M., \& Newbold, K.B. (2009). Transport mobility benefits and quality of life: a time-use perspective of elderly Canadians. Transport Policy 16 (1), 1-11.

Stanley, J.K., Hensher D.A., Stanley, J., Currie, G., Greene, W.H., \& Vella-Brodrick, D. (2011a). Social exclusion and the value of mobility. Journal of Transport Economics and Policy 45 (2), 197-222.

Stanley, J.K., Hensher, D.A., Stanley, J.R., \& Vella-Brodrick, D. (2011b). Mobility, social exclusion and well-being: exploring the links. Transportation Research Part A 45 (8), 789-801.

Stiglitz , J.E., Sen, A., \& Fitoussi, J.-P. (2009). Report by the Commission on the Measurement of Economic Performance and Social Progress, Available at: www.stiglitz-sen-fitoussi.fr.

Stutzer, A., \& Frey, B.S. (2008). Stress that doesn't pay: the commuting paradox. Scandinavian Journal of Economics 110 (2), 339-366.

Stone, A.A., Shiffman, S.S., \& Devries, M.W. (1999). Ecological Momentary Assessment. In Kahneman, D., Diener, E., Schwarz, N. (Eds.), Well-being: The Foundations of Hedonic Psychology. New York, NY: Russel Sage Foundation.

Van Acker, V., Van Wee, B., \& Witlox F. (2010). When transport geography meets social psychology: toward a conceptual model of travel behaviour. Transport Reviews 30 (2), 219-240.

van Wee, B. (2009). Self-selection: a key to a better understanding of location choices, travel behaviour and transport externalities? Transport Reviews 29 (3), 279-292.

Västfjäll, D., Friman, M., Gärling T., \& Kleiner, M. (2002). The measurement of core affect: a Swedish self-report measure. Scandinavian Journal of Psychology 43 (1), 19-31.

Västfjäll, D., \& Gärling, T. (2007). Validation of a Swedish short self-report measure. Scandinavian Journal of Psychology 48 (3), 233-238. 
Veenhoven, R. (2002). Why social policy needs subjective indicators. Social Indicators Research 58 (13), 33-46.

Waterman, A.S., Schwartz, S.J., Zamboanga, B.L., Ravert, R.D., Williams, M.K., Agocha, V.B., Kim S.Y., \& Donnellan, M.B. (2008). The questionnaire for eudaimonic well-being: psychometric properties, demographic comparisons, and evidence of validity. The Journal of Positive Psychology 5 (1), 41-61.

Watson, D., Clark, L.A., \& Tellegen, A. (1988). Development and validation of brief measures of positive and negative affects: the PANAS scales. Journal of Personality and Social Psychology 54 (6), 1063-1070.

Wener, R.E., Evans, G.W., Phillips, D., Nadler, N. (2003). Running for the 7:45: The effects of public transit improvements on commuter stress. Transportation 30 (2), 203-220.

White, M.P., \& Dolan, P. (2009). Accounting for the richness of daily activities. Psychological Science 20 (8), 1000-1008.

Ziegler, F., \& Schwanen, T. (2011). 'I like to go out to be energised by different people' :an exploratory analysis of mobility and wellbeing in later life. Ageing and Society 31 (5), 758-781. 
Table 1. Summary of the applied wellbeing scales in travel behaviour research

\begin{tabular}{|c|c|c|c|}
\hline Study & Empirical focus & What is measured? & Applied scale/method $^{1}$ \\
\hline Abou-Zeid (2009) & Travel satisfaction & $\begin{array}{l}\text { - Travel stress, travel } \\
\text { enjoyment, travel planning } \\
\text { and travel satisfaction }\end{array}$ & $\begin{array}{l}\text { Travel statements } \\
\text { (five-point scale) }\end{array}$ \\
\hline Spinney et al. (2009) & $\begin{array}{l}\text { Transport mobility and } \\
\text { quality of life }\end{array}$ & - Quality of life & $\begin{array}{l}\text { Statements measuring } \\
\text { SWB }\end{array}$ \\
\hline Currie et al. $(2009,2010)$ & $\begin{array}{l}\text { Transport disadvantage, } \\
\text { social exclusion and } \\
\text { wellbeing }\end{array}$ & $\begin{array}{l}\text { - Positive and negative affects } \\
\text { - Satisfaction with life }\end{array}$ & $\begin{array}{l}\text { PANAS } \\
\text { SWLS, PWI }\end{array}$ \\
\hline Duarte et al. (2010) & $\begin{array}{l}\text { Travel satisfaction and } \\
\text { happiness }\end{array}$ & $\begin{array}{l}\text { - Stated happiness } \\
\text { - Travel satisfaction }\end{array}$ & $\begin{array}{l}\text { Questions measuring } \\
\text { stated happiness } \\
\text { Cartoons }\end{array}$ \\
\hline Bergstad et al. (2011) & $\begin{array}{l}\text { Travel satisfaction and } \\
\text { wellbeing }\end{array}$ & $\begin{array}{l}\text { - Travel satisfaction } \\
\text { - Satisfaction with activities } \\
\text { - Satisfaction with life }\end{array}$ & $\begin{array}{l}\text { SDTS } \\
\text { SCAS } \\
\text { SWLS }\end{array}$ \\
\hline Delbosc and Currie (2011) & $\begin{array}{l}\text { Transport disadvantage, } \\
\text { social exclusion and } \\
\text { wellbeing }\end{array}$ & $\begin{array}{l}\text { - Positive and negative affects } \\
\text { - Satisfaction with life }\end{array}$ & $\begin{array}{l}\text { PANAS } \\
\text { SWLS, PWI }\end{array}$ \\
\hline Ettema et al. (2011) & $\begin{array}{l}\text { Travel satisfaction and } \\
\text { wellbeing }\end{array}$ & $\begin{array}{l}\text { - Travel satisfaction } \\
\text { - Experienced mood during } \\
\text { the day } \\
\text { - Satisfaction with life }\end{array}$ & $\begin{array}{l}\text { STS } \\
\text { SCAS } \\
\text { SWLS }\end{array}$ \\
\hline Stanley et al. (2011a, 2011b) & $\begin{array}{l}\text { Mobility, social exclusion } \\
\text { and wellbeing }\end{array}$ & $\begin{array}{l}\text { - Satisfaction with life } \\
\text { - Life meaning, personal } \\
\text { growth (PWB) }\end{array}$ & $\begin{array}{l}\text { PWI } \\
\text { PWB scale }\end{array}$ \\
\hline Abou-Zeid et al. (2012) & $\begin{array}{l}\text { Travel satisfaction and } \\
\text { attitude after travel mode } \\
\text { switching }\end{array}$ & $\begin{array}{l}\text { - Travel satisfaction } \\
\text { - attitudes toward car and } \\
\text { public transit }\end{array}$ & $\begin{array}{l}\text { Travel statements } \\
\text { (Five-point scale) } \\
\text { Statements on aspects of } \\
\text { car and public transit }\end{array}$ \\
\hline Archer et al. (2012) & $\begin{array}{l}\text { Activity-travel pattern and } \\
\text { wellbeing }\end{array}$ & - Satisfaction with life & $\begin{array}{l}\text { Measuring extent to } \\
\text { which respondents } \\
\text { experience feelings during } \\
\text { life (seven-point scale) }\end{array}$ \\
\hline Ettema et al. (2012) & $\begin{array}{l}\text { Activities during travel and } \\
\text { travel satisfaction }\end{array}$ & - Travel satisfaction & STS \\
\hline Goulias et al. (2013) & $\begin{array}{l}\text { Travel satisfaction and } \\
\text { satisfaction with activities }\end{array}$ & $\begin{array}{l}\text { - Feelings during daily } \\
\text { activities (including daily } \\
\text { trips) }\end{array}$ & $\begin{array}{l}\text { Measuring extent to } \\
\text { which respondent certain } \\
\text { feelings (seven-point } \\
\text { scale) }\end{array}$ \\
\hline Olsson et al. (2013) & $\begin{array}{l}\text { Travel satisfaction and } \\
\text { wellbeing }\end{array}$ & $\begin{array}{l}\text { - Travel satisfaction } \\
\text { - Satisfaction with life }\end{array}$ & $\begin{array}{l}\text { STS } \\
\text { SWLS }\end{array}$ \\
\hline Ravulaparthy et al. (2013) & $\begin{array}{l}\text { Participation in out-of-home } \\
\text { activities and wellbeing }\end{array}$ & - Satisfaction with life & $\begin{array}{l}\text { Statements measuring } \\
\text { satisfaction with life }\end{array}$ \\
\hline
\end{tabular}

${ }^{1}$ SDTS = Satisfaction with Daily Travel Scale; SCAS = Swedish Core Affect Scale; SWLS = Satisfaction With Life Scale; PANAS = Positive And

Negative Affect Scale; PWI = Personal Wellbeing Index; STS = Satisfaction with Travel Scale; PWS = Psychological Wellbeing Scale. 


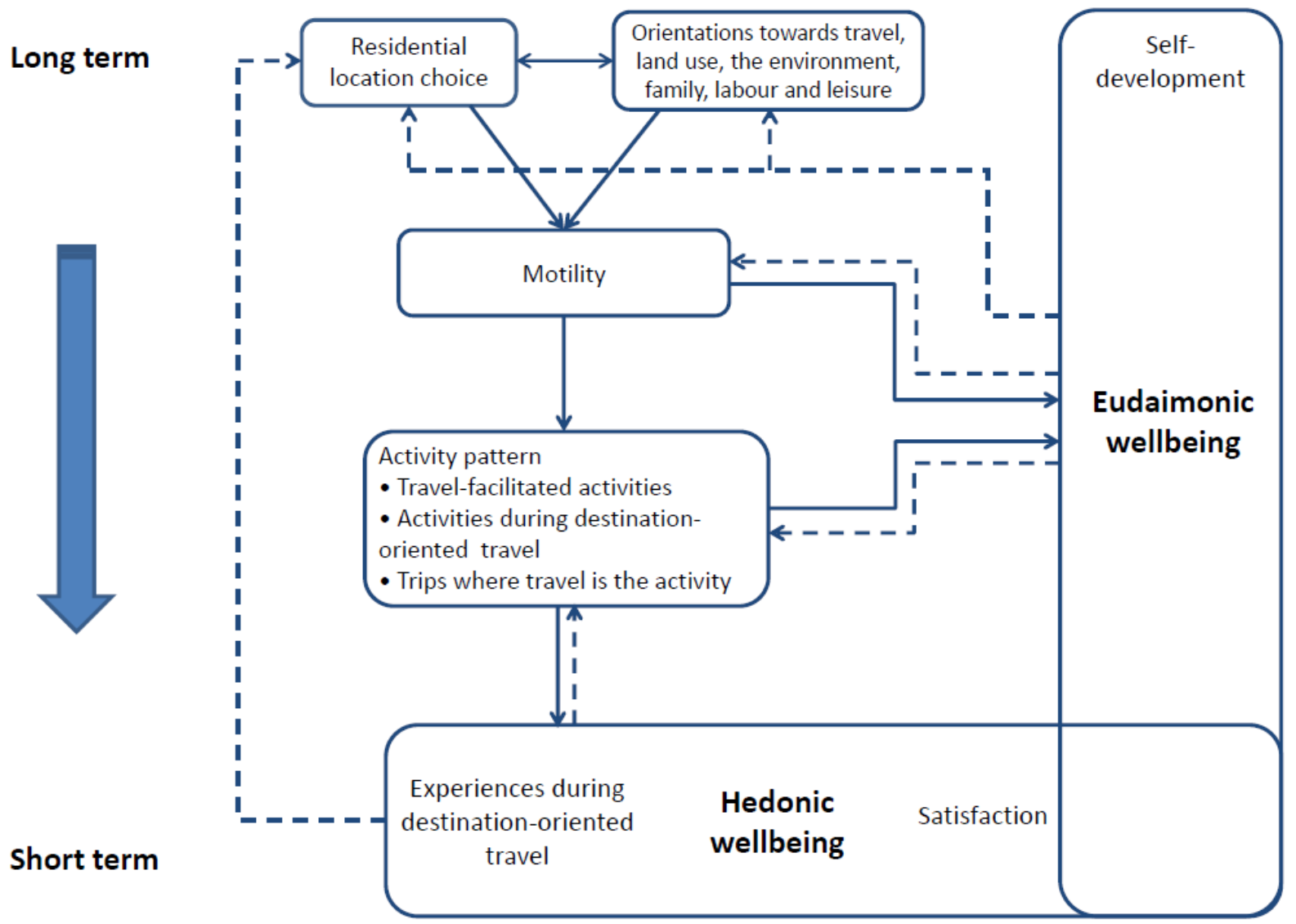

Figure 1. Theoretical model of links between travel behaviour and wellbeing 